\title{
NMR Determination of concentration-switchable inclusion complex of a $\beta$-cyclodextrin derivative carrying a benzene group linked to a $\mathrm{C}, \mathrm{C}$-glucopyranoside spacer
}

\author{
Takashi Yamanoi, ${ }^{1, *}$ Yoshiki Oda, ${ }^{2}$ and Kaname Katsuraya ${ }^{3}$ \\ ${ }^{1}$ Faculty of Pharmacy and Pharmaceutical Sciences, Josai University, 1-1 Keyakidai, Sakado, Saitama 350-0295, Japan, \\ ${ }^{2}$ Technology Joint Management Office, Tokai University, 4-1-1 Kitakaname, Hiratsuka, Kanagawa 259-1292, Japan, \\ ${ }^{3}$ Department of Human Ecology, Wayo Women's University, Chiba 272-8533, Japan
}

\begin{abstract}
This article describes the structure of the inclusion complex that a $\beta$-cyclodextrin derivative 1, which includes a benzene ring tethered to a cyclodextrin moiety via a C,C-glucopyranoside spacer, forms when its concentration is $9 \mathrm{mM}$. As we have recently reported, $\mathbf{1}$ forms an intramolecular inclusion complex at a concentration of $2 \mathrm{mM}$. By contrast, detailed NMR structural analysis revealed that at a $9 \mathrm{mM}$ concentration, 1 formed a symmetrical pseudo-dimer based on intermolecular inclusion complexiation between two molecules of 1. Thus, the inclusion structures of $\mathbf{1}$ varied depending on concentration, which indicates that the structure of this $\beta$-cyclodextrin derivative could be "concentration-switchable."
\end{abstract}

Keywords: concentration-switchable inclusion complex; $\beta$-cyclodextrin conjugated with a guest molecule; intermolecular inclusion; intramolecular inclusion

\section{Introduction}

Cyclodextrins (CyDs) are among the main host molecules in supramolecular chemistry and are known to form supramolecular inclusion complexes with various kinds of guest molecules, based on host-guest interactions [1-6]. New aspects of host-guest chemistry have been recently discovered using CyD derivatives bound covalently to a hydrophobic (guest) molecule, i.e., CyD-guest conjugates. Several studies have reported the diverse inclusion complexes formed by CyD-guest conjugates [7-15]. These complexes are fabricated from the incorporation of some parts of the guest molecule into the cavities of the CyDs via intramolecular or intermolecular inclusion interactions. Intramolecular inclusion interactions lead to the formation of self-inclusion complexes, whereas intermolecular inclusion interactions lead to the formation of noncovalently-bound pseudo-dimers or pseudo-oligomers. These CyD-based inclusion complexes often have unique structures and interesting properties. Therefore, to construct the inclusion complexes from the CyD-guest conjugates and to clarify their structures are important in CyD chemistry.

We recently reported the preparation and inclusion structure of the $\beta$-CyD derivative $\mathbf{1}$, in which a benzene group is tethered to the CyD moiety via a C,C-glucopyranoside group, as shown in Figure 1 [16]. Compound 1 was designed to be a carrier of the anti-cancer agent doxorubicin (Dox). Our detailed analysis of NMR spectral data on solutions of $\mathbf{1}$ at a 2 $\mathrm{mM}$ concentration helped us determine its inclusion complex structure. The benzene group of $\mathbf{1}$ is located over the primary side of CyD, and the sugar moiety over the benzene ring lies parallel to the axis of the CyD's cavity, as depicted in Figure 1 (I). This capped structure of $\mathbf{1}$ was a kind of self-inclusion complex resulting from the intramolecular hydrophobic interaction between the benzene group and the CyD cavity. We then showed that the formation of this selfinclusion complex considerably influenced the formation of the intermolecular inclusion complex between $\mathbf{1}$ and Dox.

We also performed NMR measurements for 1 at a $9 \mathrm{mM}$ concentration and found that the ${ }^{1} \mathrm{H}$ NMR spectrum of 1 at this concentration differed from that at a $2 \mathrm{mM}$ concentration. This evidence strongly suggested that the structure that $\mathbf{1}$ forms at a concentration of $2 \mathrm{mM}$ is different from the one it forms at a concentration of $9 \mathrm{mM}$, which indicated that the inclusion complex structure of $\mathbf{1}$ might vary depending on the concentration of the conjugate. In CyD chemistry, it is often observed that the intermolecular inclusion behaviors of CyDs with guest molecules are different according to the molar ratios and concentrations [17-20]. Concerning the CyD-guest conjugates, the conjugate concentration sometimes affects their behaviors and changes their inclusion complex structures [21-24]. Since the change of the inclusion complex structures can lead to the expression of novel functions, to provide the CyD-guest conjugates possessing "concentrationswitchable inclusion structures" is one of the current topics in CyD-based supramolecular chemistry.

This paper describes the detailed NMR structural analysis of $\mathbf{1}$ at a $9 \mathrm{mM}$ concentration. By comparing the structure of $\mathbf{1}$ at a $9 \mathrm{mM}$ concentration with our formerly reported structure of $\mathbf{1}$ at a $2 \mathrm{mM}$, we reveal the structural difference between the two concentration-dependent inclusion complexes of $\mathbf{1}$. 


\section{Experimental section}

The preparation of 1 was described in our previous paper (15). The one-dimensional (1D) ${ }^{1} \mathrm{H}$ NMR and two-dimensional (2D) rotating-frame nuclear Overhauser effect spectroscopy (ROESY) spectral measurements were performed with a 600 MHz JEOL ECA-600 FT-NMR spectrometer at $298 \mathrm{~K}$. The 1D spectrum was obtained with 16 scans. The conditions for collecting the 2D ROESY spectrum were as follows: 5120 scans; mixing time $250 \mathrm{~ms}$; spectral width $9000 \mathrm{~Hz}$; data size $1024\left(F_{2}\right) / 256\left(F_{1}\right)$; relaxation delay $1.5 \mathrm{~s}$. The MALDI-TOF-MS spectrum was recorded by a Voyager DE STR spectrometer (Method: LDE1005; Mode: Linear; Laser: 2500; Positive mode). MALDI targets were prepared using 2,5dihydroxybenzoic acid (DHB) as the matrix and implementing the dried droplet method. Compound $\mathbf{1}$ was dissolved in $\mathrm{H}_{2} \mathrm{O}$ at a concentration of $9 \mathrm{mM}$. Then, $1 \mu \mathrm{L}$ of 1 at a $9 \mathrm{mM}$ concentration was deposited on the MALDI target and allowed to dry in vacuum. The DHB solution was prepared by dissolving the compound in $\mathrm{H}_{2} \mathrm{O}(0.1 \%$ TFA, $1 \mathrm{mg} / \mathrm{mL})$. Finally, $1 \mu \mathrm{L}$ of the DHB solution was deposited on the MALDI target of the spot of $\mathbf{1}$ and allowed to dry in vacuum.

\section{Results and discussion}

Figures 2 (i) and (ii) depict the ${ }^{1} \mathrm{H}$ NMR spectra of 1 at a concentration of $2 \mathrm{mM}$ and $9 \mathrm{mM}$ in $\mathrm{D}_{2} \mathrm{O}$, respectively. Some of the ${ }^{1} \mathrm{H}$ NMR spectral patterns of the solutions at the two concentrations were different from each other, and we proceeded to assign in detail the ${ }^{1} \mathrm{H}$ NMR chemical shifts of the $9 \mathrm{mM}$ solution of $\mathbf{1}$. This assignment was performed by one- and two-dimensional NMR spectroscopic techniques, including ${ }^{1} \mathrm{H} N M R,{ }^{1} \mathrm{H}-{ }^{1} \mathrm{H}$ COSY, and TOCSY (data not shown). Table 1 shows the ${ }^{1} \mathrm{H}$ NMR chemical shift assignments of $\mathbf{1}$ at a $9 \mathrm{mM}$ concentration along with those of the 2 $\mathrm{mM}$ concentration solution that we previously reported. The ${ }^{1} \mathrm{H}$ NMR assignments clarified the differences in chemical shift of the proton signals of $\mathbf{1}$ observed at the two concentrations. Some specific proton signals attributed to the benzene ring and to the spacer at $\mathrm{C} 2^{\prime}-\mathrm{C}^{\prime}$ at a $9 \mathrm{mM}$ concentration were shifted, compared with their counterparts at a $2 \mathrm{mM}$ concentration. Figure 2 (iii) depicts the ${ }^{1} \mathrm{H}$ NMR spectrum of 1 at a $9 \mathrm{mM}$ concentration in $\mathrm{CD}_{3} \mathrm{OD}$. In this solvent, where no inclusion association is expected to occur, the ortho-, meta- and para-proton signals of the benzene moiety were observed as three separate peaks. The ${ }^{1} \mathrm{H}$ NMR spectral pattern of $\mathbf{1}$ in $\mathrm{CD}_{3} \mathrm{OD}$ was quite different from that observed in $\mathrm{D}_{2} \mathrm{O}$. This evidence strongly suggests that the benzene ring moiety of $\mathbf{1}$ is involved in some inclusion association in $\mathrm{D}_{2} \mathrm{O}$ when the concentration of $\mathbf{1}$ is $9 \mathrm{mM}$. We also found that the supramolecular structure that $\mathbf{1}$ forms at a concentration of $9 \mathrm{mM}$ in $\mathrm{D}_{2} \mathrm{O}$ is different from the one it forms at a concentration of $2 \mathrm{mM}$ in the same solvent.

To reveal the inclustion complex structure of 1 at a $9 \mathrm{mM}$ concentration in $\mathrm{D}_{2} \mathrm{O}$, we performed a ROESY experiment. Figure 3 reports the ROESY spectrum of $\mathbf{1}$ at a $9 \mathrm{mM}$ concentration in $\mathrm{D}_{2} \mathrm{O}$ at $25^{\circ} \mathrm{C}$. Some observed long-range ROE interactions $(\mathrm{a}-\mathrm{h})$ are summarized in Table 2 . The conformational structure of $\mathbf{1}$ inferred from the observed ROE signals (a) and $(\mathrm{d}-\mathrm{h})$ is reported in Figure 4. The ROE signal (a) results from the interaction between the proton of the benzene ring and the Ha9', which shows that the plane of the benzene ring is likely to be nearly parallel to the $\mathrm{C}^{\prime}-\mathrm{Ha}^{\prime}$ ' bond axis and to be in a coplanar conformation. The ROE signal (g) results from the interaction between the $\mathrm{H} 4^{\prime}$ and the Hb9'. ROE signals similar to (a) and (g) were also observed in the previously reported ROESY spectrum of 1 at a $2 \mathrm{mM}$ concentration. Therefore, the conformational structures around the sugar ring-C9'-benzene ring of $\mathbf{1}$ are essentially the same for the two concentrations of the conjugate.

The ROE signals $(\mathrm{d}-\mathrm{f})$ and $(\mathrm{h})$ were characterized at a $9 \mathrm{mM}$ concentration of $\mathbf{1}$. Signal (d) resulted from the ROE interaction between $\mathrm{Ha}^{\prime}$ and $\mathrm{H}^{\prime}$, and signals (e) and (f) resulted from the ROE interactions of the $\mathrm{Hb} 2^{\prime}$ with $\mathrm{H}^{\prime}$ ' and $\mathrm{H}^{\prime}$ ', respectively. On the other hand, no corresponding ROE signals were observed at all in the ROE spectrum of $\mathbf{1}$ at a 2 $\mathrm{mM}$ concentration. This evidence indicates that the conformational structures of the spacer part around the $\mathrm{C}^{\prime}-\mathrm{C} 2^{\prime}$ containing the amide bond are remarkably different at the two concentrations. Furthermore, signal (h) results from the ROE interaction between Ha9' and the $\mathrm{H} 4$ on the glucose moiety of CyD linked with a C,C-glucopyranoside group. This means that the section of the structure that transforms from the sugar ring to the benzene ring bound to CyD is positioned outside the CyD cavity and that the benzene ring is conformationally parallel to the secondary side rim of $\mathrm{CyD}$, as shown in Figure 4 (II). This structure is different from that formed by a solution of 1 at a $2 \mathrm{mM}$ concentration, which is reported in Figure 1 (I). The proposed conformational structure of 1 at a $9 \mathrm{mM}$ concentration reported in Figure 4 might be one of the stable structures that occur when the host-guest intramolecular interaction between the benzene ring and the CyD cavity does not take place.

The observed ROE signals (b) and (c) result from the interactions between the proton of the benzene ring and the $\mathrm{H} 3$ proton of the glucose moiety of CyD linked with a C,C-glucopyranoside group. The ROE observations mean that the benzene ring is located near the secondary side of the $\mathrm{CyD}$ cavity. This conclusion is also supported by the features of the ${ }^{1} \mathrm{H}$ NMR spectrum. The ROE signals (b) and (c) and the above-mentioned ROE signals (a) and (d-h) indicate that 1 at $9 \mathrm{mM}$ forms some kind of oligomer based on the intermolecular interaction between the benzene ring and the CyD cavity. To identify the oligomer, we measured the molecular weight of the oligomer using MALDI-TOF MS spectrometry. When the sample including 1 described in Experimental section was measured, the MALDI-TOF MS 
spectrum showed a $[2 \mathrm{M}+\mathrm{Na}]$ ion peak at $\mathrm{m} / \mathrm{z} 2877$ in addition to a $[\mathrm{M}+\mathrm{Na}]$ ion peak at $\mathrm{m} / \mathrm{z} 1452$. There was no observation of the ion peak showing a bigger molecular weight than the $[2 \mathrm{M}+\mathrm{Na}]$ ion peak. Therefore, we could confirm that a dimer from 1 was formed as the result of the intermolecular inclusion complexiation between two molecules of $\mathbf{1}$. Furthermore, the ${ }^{1} \mathrm{H}$ NMR spectrum of $\mathbf{1}$, see Figure 2 (ii), strongly indicates the formation of a single structure, so we concluded that a symmetric pseudo-dimer structure formed at a $9 \mathrm{mM}$ concentration, whereby each of the two benzene ring units cap the secondary side of the CyD cavity of the other member of the 1-1 dimer, as shown in Figure 5 (III). At a $9 \mathrm{mM}$ concentration, the intermolecular interaction increases and promotes the formation of the intermolecular inclusion complex from two molecules of $\mathbf{1}$.

The molecular modeling of the pseudo-dimer of $\mathbf{1}$ is reported in Figure 6. Molecular modeling calculations were performed using the molecular force field method with MMFF94 which was installed on the Avogadro Application Ver. 1.1.1. Stabilization energy $(\Delta \mathrm{E})$ upon formation of the pseudo-dimer of $\mathbf{1}$ was calculated to be $-274 \mathrm{~kJ} / \mathrm{mol}$, according to Eq. $\Delta \mathrm{E}=\mathrm{E}_{\mathrm{dimer}}-2 \times \mathrm{E}_{\text {monomer }}$, where $\mathrm{E}_{\mathrm{dimer}}$ and $\mathrm{E}_{\text {monomer }}$ represent optimized total potential energies of the minimum pseudo-dimeric structure and monomeric capped structure from $\mathbf{1}$.

\section{Conclusions}

We found that the $\beta$-CyD derivative 1 , which includes a benzene ring tethered to a $\mathrm{CyD}$ moiety via a C,Cglucopyranoside spacer, formed a symmetrically structured pseudo-dimer through the intermolecular inclusion complexiation between two molecules of 1 at a $9 \mathrm{mM}$ concentration. The supramolecular structure of 1 at a $9 \mathrm{mM}$ concentration was quite different from that observed at a $2 \mathrm{mM}$ concentration. Thus, compound $\mathbf{1}$ is a molecule whose inclusion structure is concentration-switchable. We believe this study can provide the information as to the development of novel CyD-guest conjugates which have useful functions based on the concentration-switchable supramolecular structures.

\section{References}

1. Zheng, Y., Wyman, I.W.: Review: Supramolecular nanostructures based on cyclodextrin and poly(ethylene oxide): Syntheses, structural characterizations and applications for drug delivery. Polymers 8, 198/1-198/18 (2016)

2. Crini, G.: A history of cyclodextrins. Chem. Rev. 114, 10940-10975 (2014)

3. Guiou, S., Sollogoub, M.: Advances in cyclodextrin chemistry. In: Werz, D. B., Vidal, S. (eds.) In Modern Synthetic Methods in Carbohydrate Chemistry, pp 241-283. Wiley-VCH Verlag GmbH \& Co. KGaA, Weinheim (2014).

4. Lincoln, S.F., Pham, D.-T.: Cyclodextrins: from nature to nanotechnology. In Gale, P.A., Steed, J.W. (eds.) In Supramolecular Chemistry: From Molecules to Nanomaterials Vol.3, pp 954-981. John Wiley \& Sons Ltd., Chichester (2012)

5. Wallimann, P., Marti, T., Fuerer, A., Diederich, F.: Steroids in molecular recognition. Chem. Rev. 97, 1567-1608 (1997)

6. Uekama, K., Hirayama, F., Arima, H.: Pharmaceutical applications of cyclodextrins and their derivatives. In Dodziuk, H. (ed) In Cyclodextrins and Their Complexes, pp 381-422. Wiley-VCH Verlag GmbH \& Co. KGaA, Weinheim (2008)

7. Benkovics G., Hodek O., Havlikova M., Bosakova Z., Coufal P., Malanga M., Fenyvesi E., Darcsi A., Beni S., Jindrich J.: Supramolecular structures based on regioisomers of cinnamyl- $\alpha$-cyclodextrins-new media for capillary separation techniques. Beilstein J. Org. Chem. 12, 97-109 (2016)

8. Malanga, M., Darcsi, A., Balint, M., Benkovics, G., Sohajda, T., Beni, S.: New synthetic strategies for xanthene-dyeappended cyclodextrins. Beilstein J. Org. Chem. 12, 537-548 (2016)

9. Engeldinger, E., Armspach, D., Matt, D.: Capped cyclodextrins. Chem. Rev. 103, 4147-4173 (2003)

10. Harada, A., Hashidzume, A., Takashima, Y.: Cyclodextrin-based supramolecular polymers. Adv. Polym. Sci. 201, 143 (2006).

11. Liu, Y., Fan, Z., Zhang, H.-Y., Yang, Y.-W. Ding, F. Liu, S.-X., Wu, X., Wada, T., Inoue, Y.: Homodimerization and heteroassociation of 6-O-(2-sulfonato-6-naphthyl)- $\gamma$-cyclodextrin and 6-deoxy-(pyrene-1-carboxamido)- $\gamma$-cyclodextrin. J. Org. Chem. 68, 8345-8352 (2003).

12. Harada, A., Miyauchi, M., Hoshino, T.: Supramolecular polymers formed by cinnamoy cyclodextrins. J. Polym Sci. A Polym. Chem. 41, 3519-3523 (2003).

13. Tanabe, T., Usui, S., Nakamura, A., Ueno, A.: The stability of self-inclusion complexes of cyclodextrin derivatives bearing a p-dimethylaminobenze moiety. J. Incl. Phenom. Macrocycl. Chem. 36, 79-93 (2000).

14. Kuwabara, T., Shiba, K., Nakajima, H., Ozawa, M., Miyajima, N., Hosoda, M., Kuramoto, N., Suzuki, Y.: Host-guest complexation affected by $\mathrm{pH}$ and length of spacer for hydroxyazobenzene-modified cyclodextrins. J. Phys. Chem. A 110 , 13521-13529 (2006). 
15. Park, J.W., Lee, S.Y., Song, H.J., Park, K. K.: Self-inclusion behavior and circular dichroism of aliphatic chainlinked $\beta$-cyclodextrin-viologen compounds and their reduced forms depending on the side of modification. J. Org. Chem. 70, 9505-9513 (2005). Others references cited therein.

16. Yamanoi, T., Oda, Y., Katsuraya, K., Inazu, T., Hattori, K.: Synthesis, structure, and evaluation of a $\beta$-cyclodextrinartificial carbohydrate conjugate for use as a doxorubicin-carrying molecule. Bioorg. Med. Chem. 24, 635-642 (2016). 17. Akita, T., Yoshikiyo, K., Yamamoto, T.: Formation of 1:1 and 2:1 host-guest inclusion complexes of $\alpha-$ cyclodextrin with cycloalkanols: A ${ }^{1} \mathrm{H}$ and ${ }^{13} \mathrm{C}$ NMR spectroscopic study. J. Mol. Struct. 1074, 43-50 (2014).

18. Akita, T., Matsui, Y., Yamamoto, T.: A ${ }^{1} \mathrm{H}$ NMR titration study on the binding constants for D- and L-tryptophan inclusion complexes with 6-O- $\alpha$-D-glucosyl- $\beta$-cyclodextrin. Formation of 1:1 and 2:1 (host:guest) complexes, J. Mol. Struct. 1060, 138-141 (2014).

19. Nakamura, A., Inoue, Y.: Supramolecular catalysis of the enantiodifferentiating [4+4] photocyclodimerization of 2anthracenecarboxylate by $\gamma$-cyclodextrin. J. Am. Chem. Soc. 125, 966-972 (2003).

20. Utsuki, T., Hirayama, F., Uekama, K.: Different photodimerization behaviour of tranilast in $\alpha$-, $\beta$ - and $\gamma$-cyclodextrin complexes: Cavity-size and stoichiometry dependence. J. Chem. Soc. Perkin Trans. 2 109-114 (1993).

21. Miyauchi, M., Hoshino, T., Yamaguchi, H., Kamitori, S., Harada, A.: A [2]rotaxane capped by a cyclodextrin and a guest: formation of supramolecular [2]rotaxane polymer. J. Am. Chem. Soc. 127, 2034-2035 (2005).

22. Miyauchi, M., Harada, A.: Construction of supramolecular polymers with alternating $\alpha$-, $\beta$-cyclodextrin units using conformational change induced by competitive guests. J. Am. Chem. Soc. 126, 11418-11419 (2004).

23. Carofiglio, T., Fornasier, R., Gennari, G., Lucchini, V., Simonato, L., Tonellato, U.: Synthesis and spectroscopic properties of a water-soluble porphyrin-modified $\beta$-cyclodextrin compound. Tetrahedron Lett. 38, 7919-7922 (1997). 24. Self-association of a naphthalene-capped- $\beta$-cyclodextrin through cooperative strong hydrophobic interactions, González-Álvarez, M. J., Méndez-Ardoy, A., Benito, J. M., Fernández, J.M.G., Mendicuti, F.: J. Photochem. Photobiol. A 223, 25-36 (2011). 
Table 1. Chemical shift assignments of ${ }^{1} \mathrm{H}$ NMR spectra of solutions of $\mathbf{1}$ at concentrations of $9 \mathrm{mM}$ and $2 \mathrm{mM}$

\begin{tabular}{|c|c|c|c|c|}
\hline \multirow{2}{*}{$\begin{array}{l}\text { Compound } \\
\mathbf{1}\end{array}$} & \multirow{2}{*}{ Proton } & \multicolumn{2}{|c|}{ Chemical shift } & \multirow{2}{*}{$\begin{array}{l}\text { Chemical shift change } \\
\text { Upfield (+)/ppm } \\
\text { Downfield (-)/ppm }\end{array}$} \\
\hline & & $9 \mathrm{mM}$ concentration & $2 \mathrm{mM}$ concentration & \\
\hline CyD unit & $\begin{array}{l}\text { H1 } \\
\text { H2 } \\
\text { H3 } \\
\text { H4 } \\
\text { H5 } \\
\text { H6 }\end{array}$ & $\begin{array}{l}4.91[\mathrm{~A}], 4.94[\mathrm{G}], 4.89,4.90, \\
4.91,4.92,4.92 \\
3.49[\mathrm{~A}], 3.42[\mathrm{G}], 3.43,3.45, \\
3.46,3.47,3.51 \\
3.73[\mathrm{~A}], 3.58,3.63,3.69,3.77, \\
3.79,3.80 \\
3.23[\mathrm{~A}: \mathrm{t}, 9.6], 3.47[\mathrm{~B}], 3.51, \\
\text { 3.53, 3.57, 3.74, 3.75 } \\
\text { 3.55 [A-5], 3.69 [A-6], 3.71 [A- } \\
\text { 6], 3.56, 3.61, 3.63, 3.64, 3.65, } \\
\text { 3.67, 3.67, 3.68, 3.68, 3.73, } \\
\text { 3.74, 3.75, 3.76, 3.77, 3.78, } \\
\text { 3.79, 3.82, 3.83 }\end{array}$ & $\begin{array}{l}\text { 4.87 [d, 2.8], 4.89, 4.89, 4.90, } \\
4.91,4.91,4.99[\mathrm{~d}, 2.8] \\
3.40,3.41,3.51,3.52,3.55, \\
3.57,3.59 \\
3.82,3.82,3.84,3.88,3.88, \\
3.90,3.94 \\
3.20[\mathrm{~A}: \mathrm{t}, 9.0], 3.46,3.48, \\
3.49,3.53,3.54,3.57 \\
3.56,3.61,3.68,3.68,3.69, \\
3.69,3.73 \\
3.63,3.64,3.67,3.68,3.69, \\
3.71,3.75,3.76,3.77,3.78, \\
3.785,3.81,3.82,3.89\end{array}$ & \\
\hline $\begin{array}{l}\text { C,C-Glucosyl } \\
\text { unit }\end{array}$ & $\begin{array}{l}\mathrm{Ha} 2^{\prime} \\
\mathrm{Hb} 2^{\prime} \\
\mathrm{H}{ }^{\prime}, \\
\mathrm{H}{ }^{\prime}, \\
\mathrm{H}{ }^{\prime} \\
\mathrm{H}{ }^{\prime} \\
\mathrm{Ha} 8^{\prime} \\
\mathrm{Hb} 8^{\prime} \\
\mathrm{Ha} \\
\mathrm{Hb} \\
\mathrm{Hc} \\
\mathrm{Ha} 9 \\
\mathrm{Hb} 9\end{array}$ & $\begin{array}{l}2.56[\mathrm{~d}, 15.1] \\
2.67[\mathrm{~d}, 15.1] \\
3.08[\mathrm{~d}, 9.7] \\
3.45 \\
3.68 \\
3.51 \\
2.94[\mathrm{~m}] \\
3.05[\mathrm{~m}] \\
7.12 \sim 7.20 \\
2.95[\mathrm{~d}, 14.4] \\
2.75[\mathrm{~d}, 14.4]\end{array}$ & $\begin{array}{l}2.54[\mathrm{~d}, 15.8] \\
2.60[\mathrm{~d}, 15.8] \\
3.08[\mathrm{~d}, 9.6] \\
3.45 \\
3.47 \\
3.76 \\
2.89[\mathrm{~m}] \\
3.02[\mathrm{~m}] \\
7.19[\mathrm{bs}] \\
7.21[\mathrm{bs}] \\
7.15[\mathrm{bs}] \\
2.95[\mathrm{~d}, 14.5] \\
2.70[\mathrm{~d}, 14.4]\end{array}$ & $\begin{array}{l}-0.21 \\
+0.25 \\
-0.05 \\
-0.03\end{array}$ \\
\hline
\end{tabular}

Table 2. ROESY interaction signals from a solution of $\mathbf{1}$ at a $9 \mathrm{mM}$ concentration

\begin{tabular}{|c|c|}
\hline ROESY signal & ROE Interactions \\
\hline $\mathrm{a}$ & Benzene-H $\leftrightarrow$ Ha9' \\
\hline $\mathrm{b}$ & Benzene-H $\leftrightarrow$ CyD-H3 \\
\hline $\mathrm{c}$ & Benzene- $\mathrm{H} \leftrightarrow$ CyD-H3 \\
\hline d & $\mathrm{Ha} 2^{\prime} \leftrightarrow \mathrm{H}^{\prime}{ }^{\prime}$ \\
\hline $\mathrm{e}$ & $\mathrm{Hb} 2^{\prime} \leftrightarrow \mathrm{H}^{\prime}$ \\
\hline$f$ & $\mathrm{Hb} 2^{\prime} \leftrightarrow \mathrm{H}^{\prime}$ \\
\hline $\mathrm{g}$ & $\mathrm{Hb}^{\prime}{ }^{\prime} \leftrightarrow \mathrm{H} 4^{\prime}$ \\
\hline $\mathrm{h}$ & $\mathrm{Ha}^{\prime} \leftrightarrow \mathrm{CyD}[\mathrm{A}]-\mathrm{H} 4$ \\
\hline
\end{tabular}



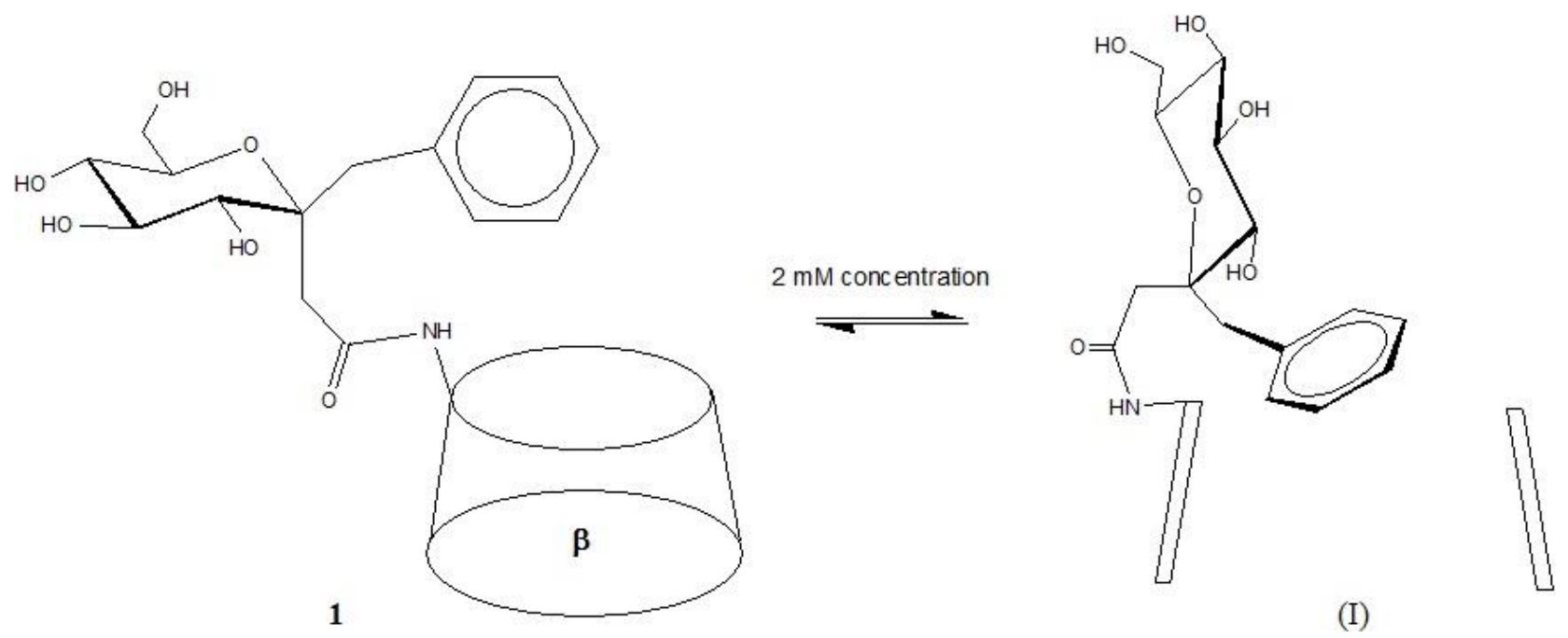

Fig 1. Self-inclusion structure of $\mathbf{1}$ at a $2 \mathrm{mM}$ concentration

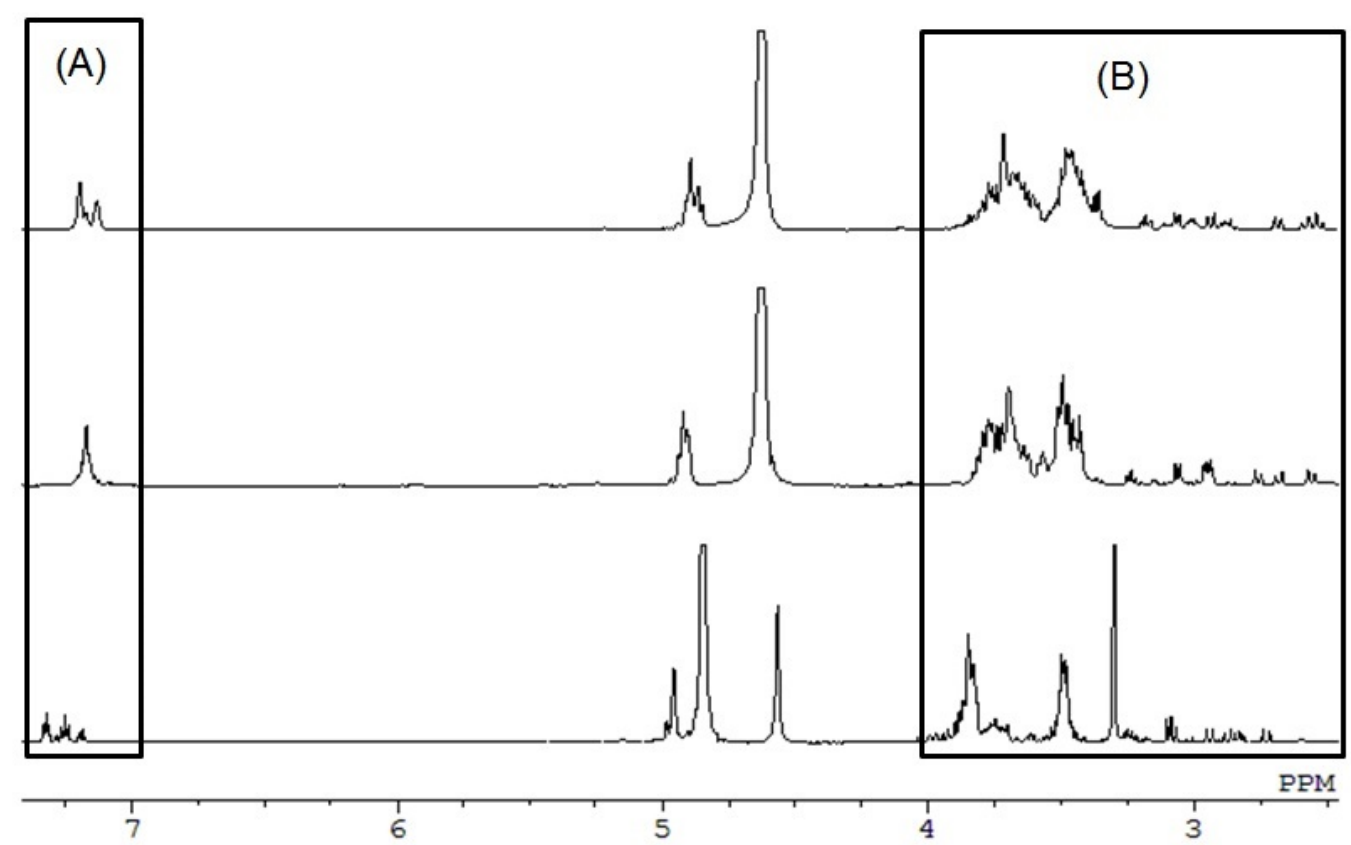

(i)

(ii)

(iii)

Fig 2 (a). 

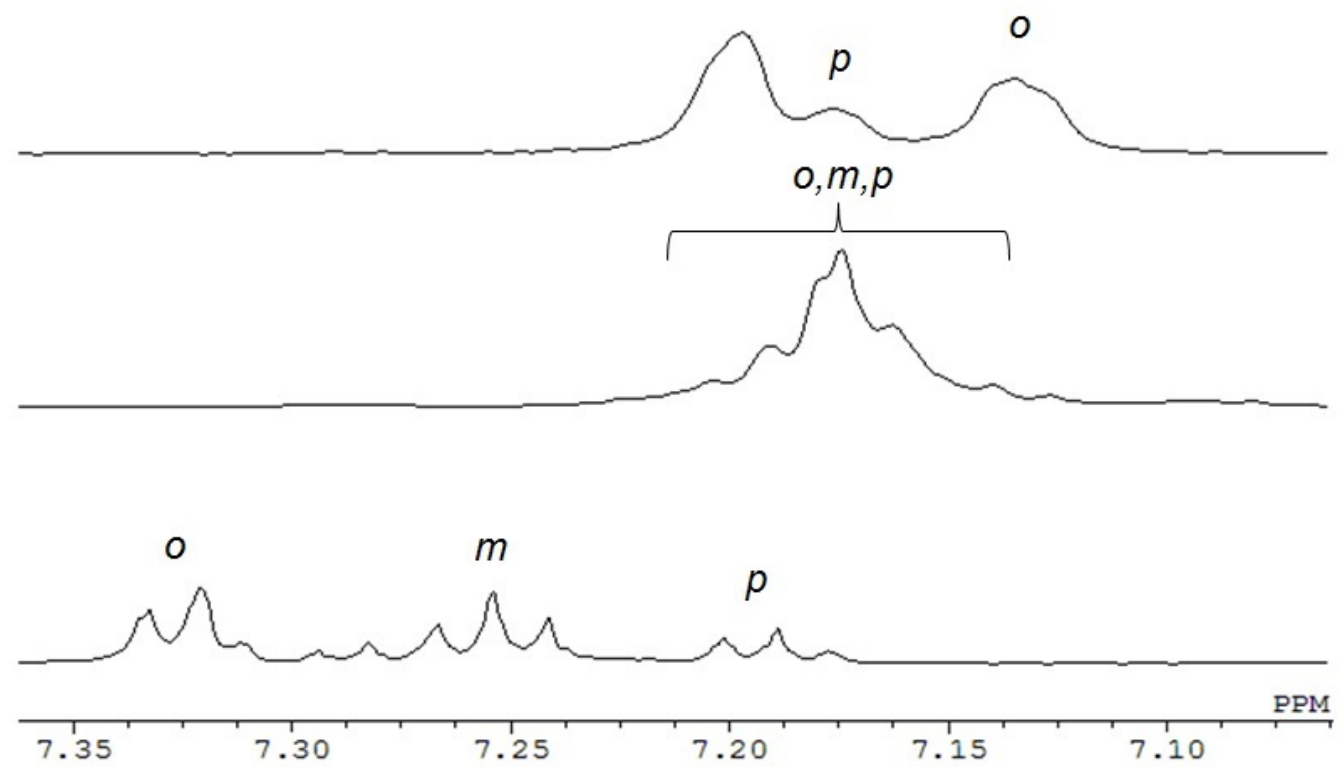

Fig 2 (b).

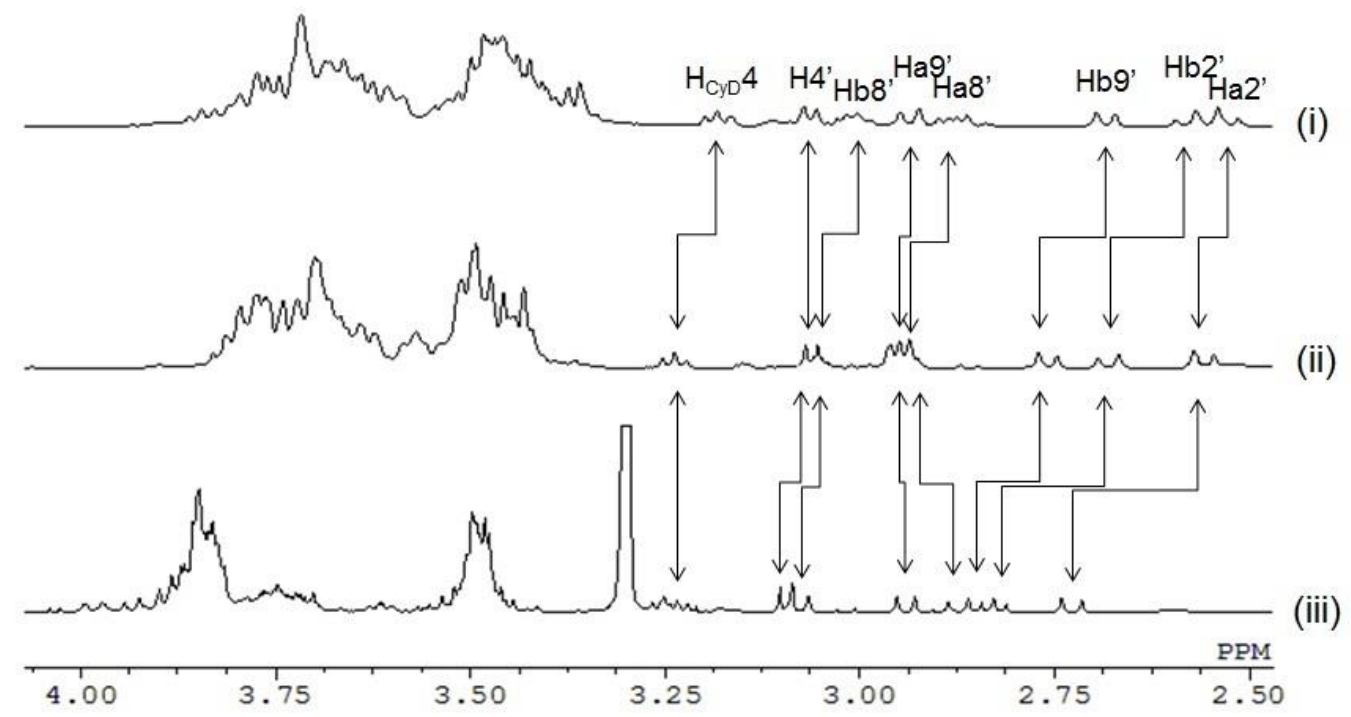

Fig 2 (c).

Fig 2. (a) ${ }^{1} \mathrm{H}$ NMR spectrum of $\mathbf{1}$ : (i) $2 \mathrm{mM}$ concentration in $\mathrm{D}_{2} \mathrm{O}$; (ii) $9 \mathrm{mM}$ concentration in $\mathrm{D}_{2} \mathrm{O}$; (iii) $9 \mathrm{mM}$ concentration in $\mathrm{CD}_{3} \mathrm{OD}$. (b) Expansion of section (A) from (a). (c) Expansion of section (B) from (a) 


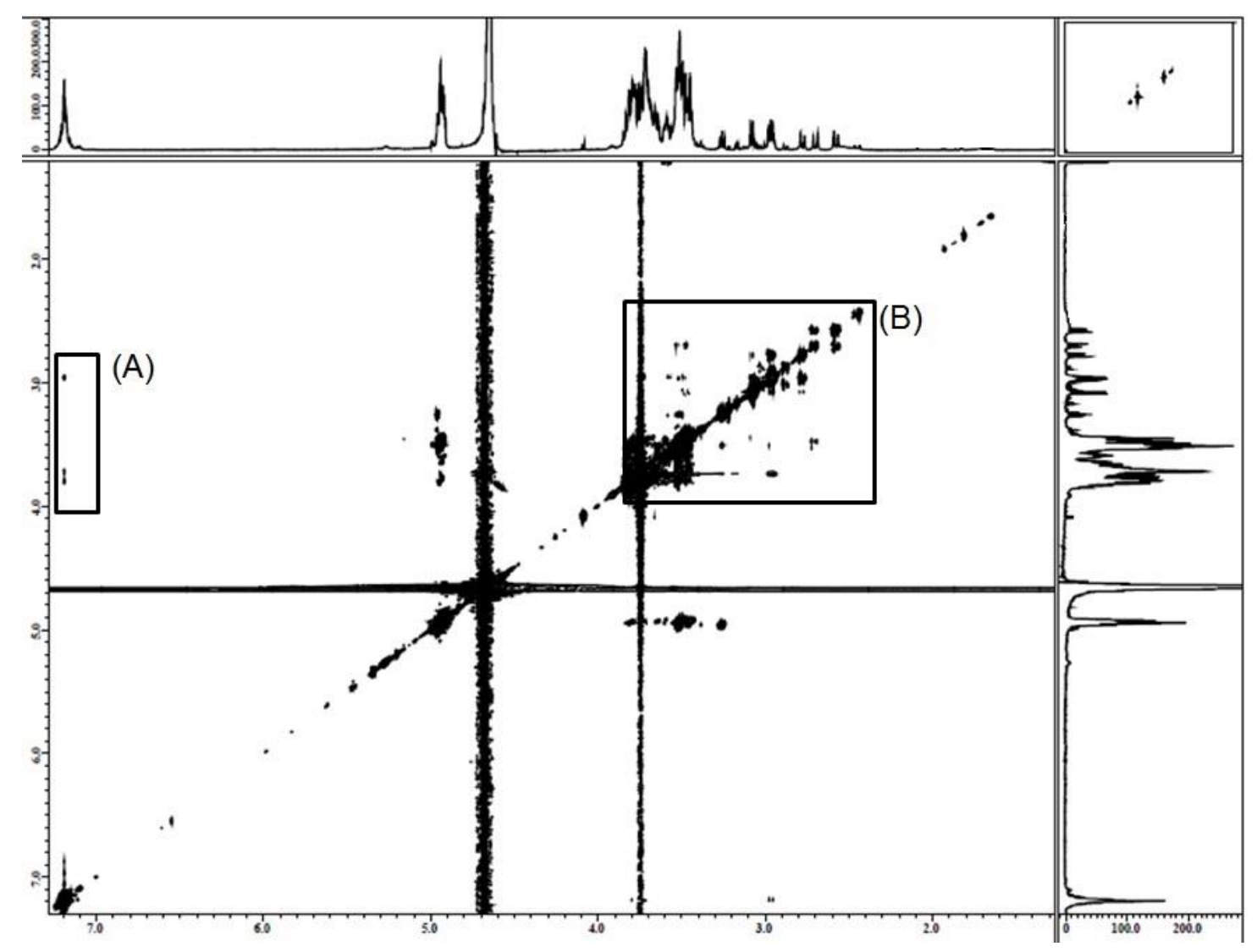

Fig 3 (a).

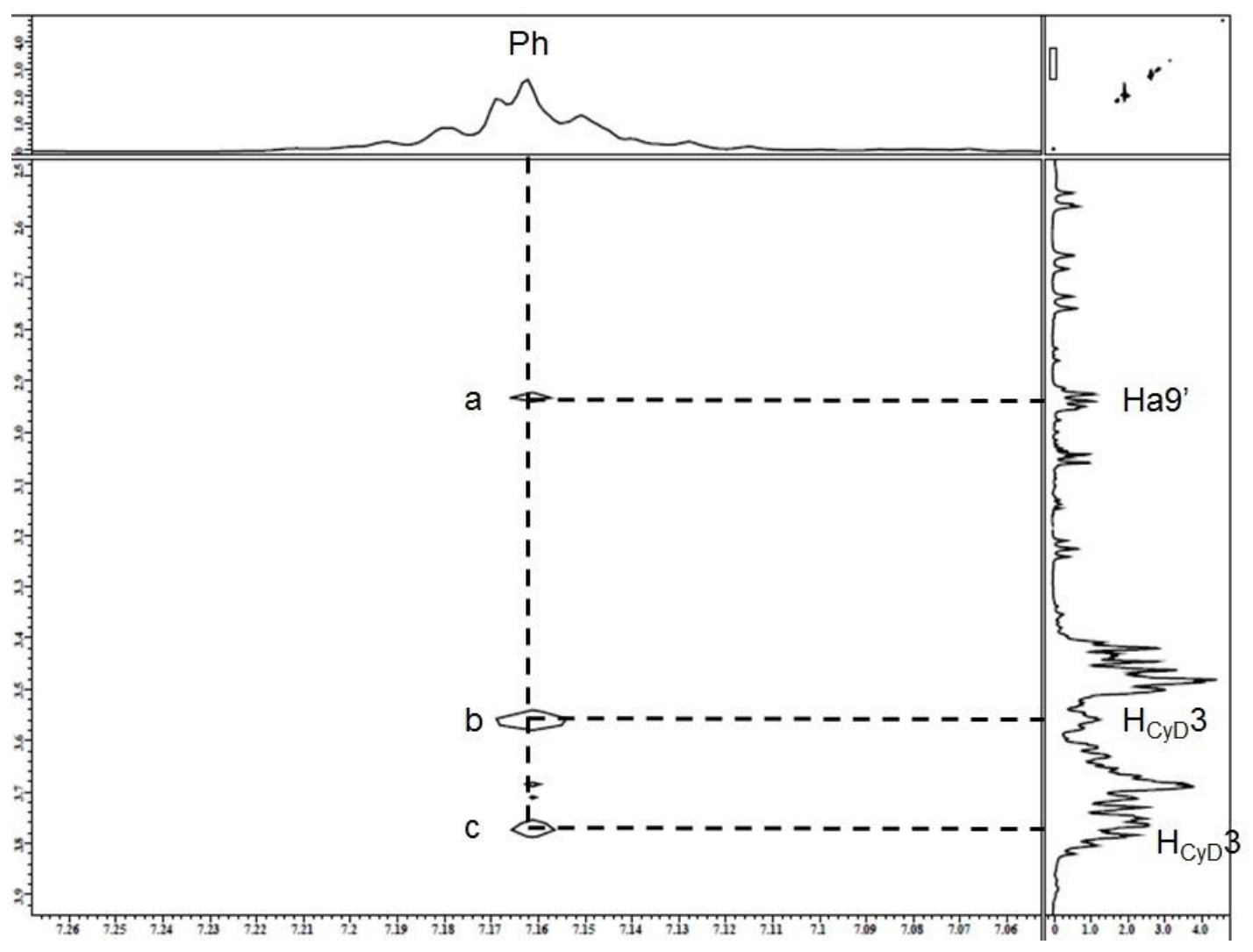

Fig 3 (b). 


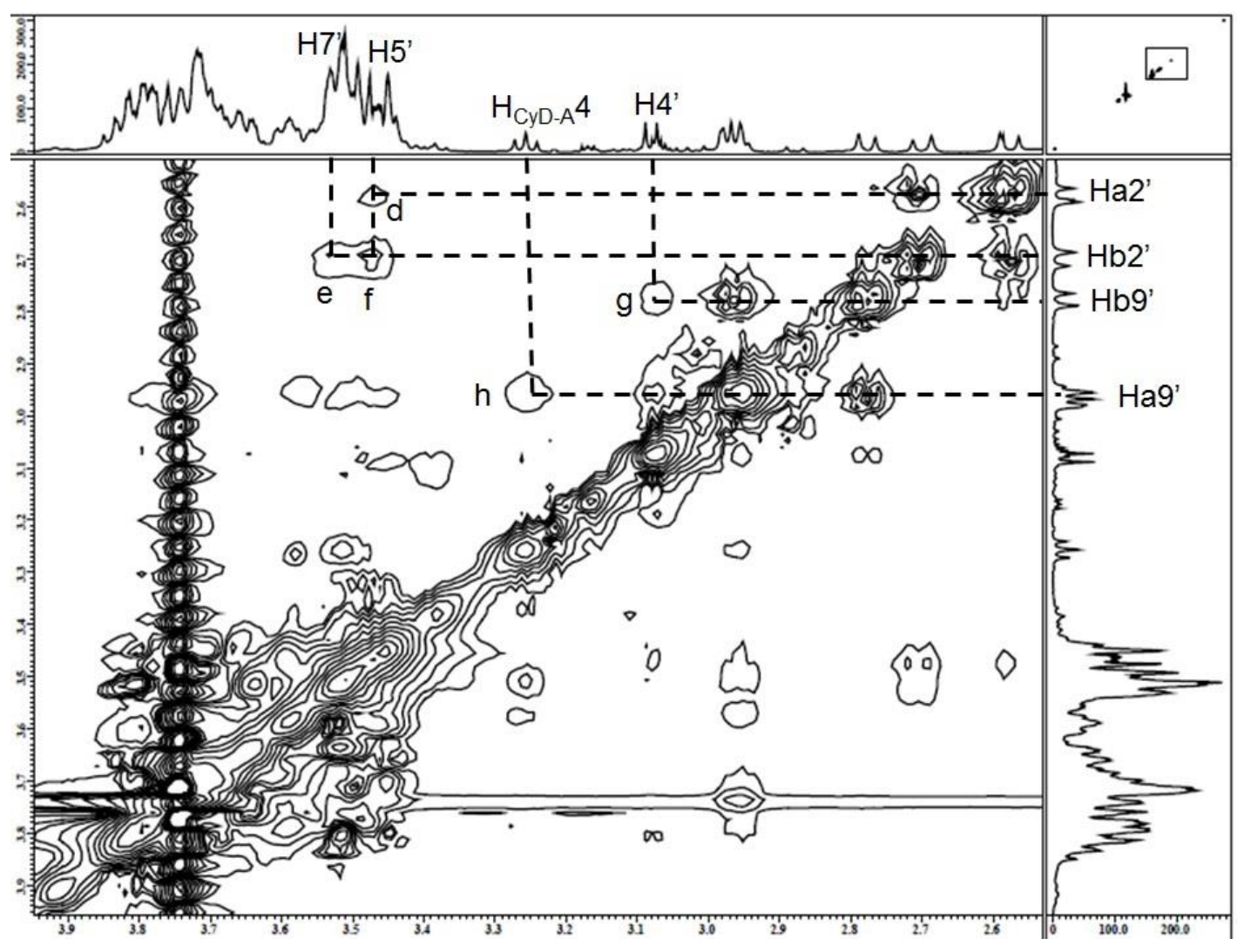

Fig 3 (c).

Fig 3. (a) ROESY spectrum of 1 at a $9 \mathrm{mM}$ concentration: (b) Expansion of section (A) from (a). (c) Expansion of section (B) from (a) 


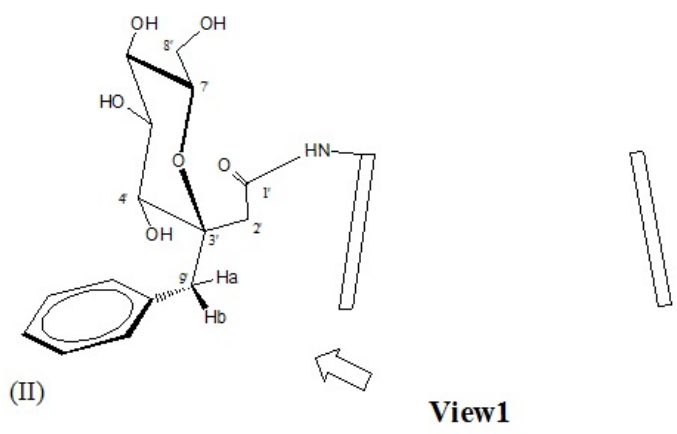

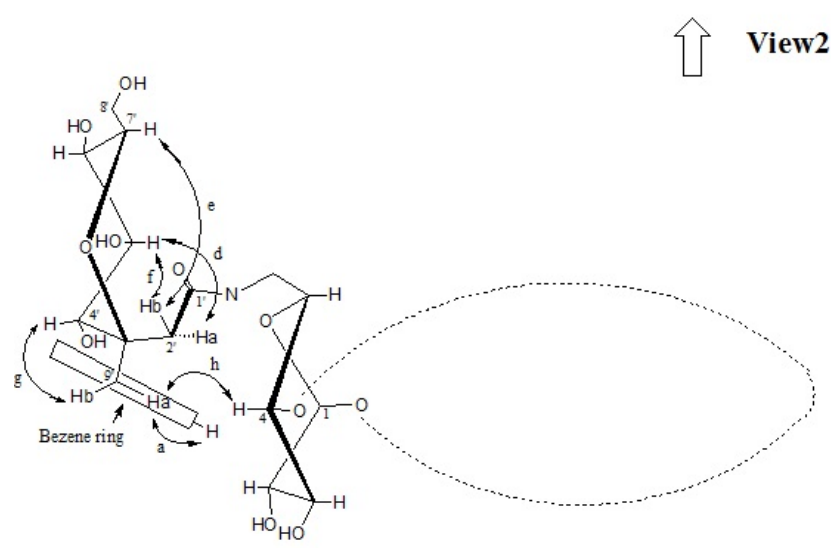

View1

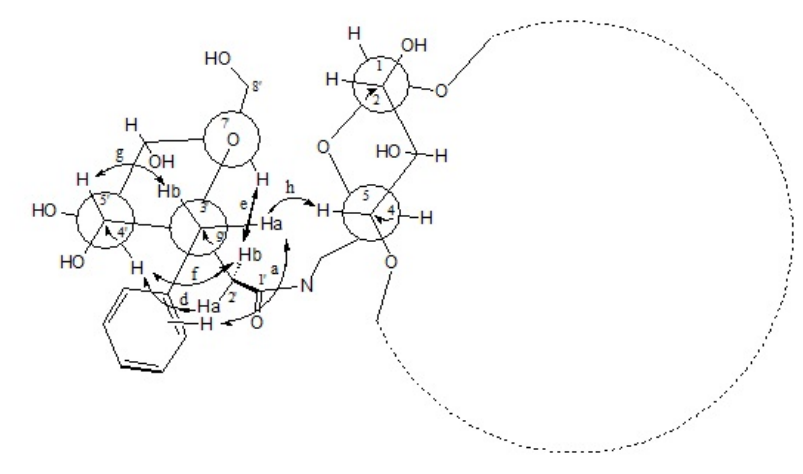

View2

Fig 4. Monomeric conformational structure of $\mathbf{1}$ at a $9 \mathrm{mM}$ concentration inferred from the ROESY interactions
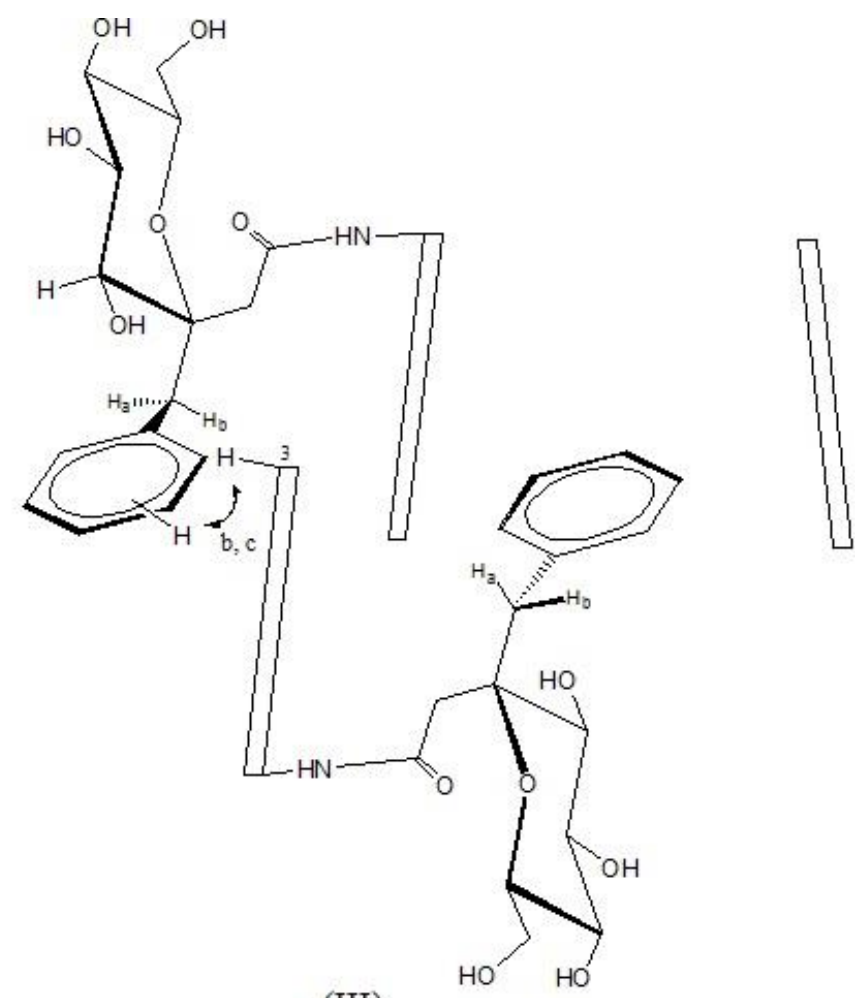

(III)

Fig 5. Speculated pseudo-dimeric structure resulting from the intermolecular inclusion complexiation between two molecules of $\mathbf{1}$ 

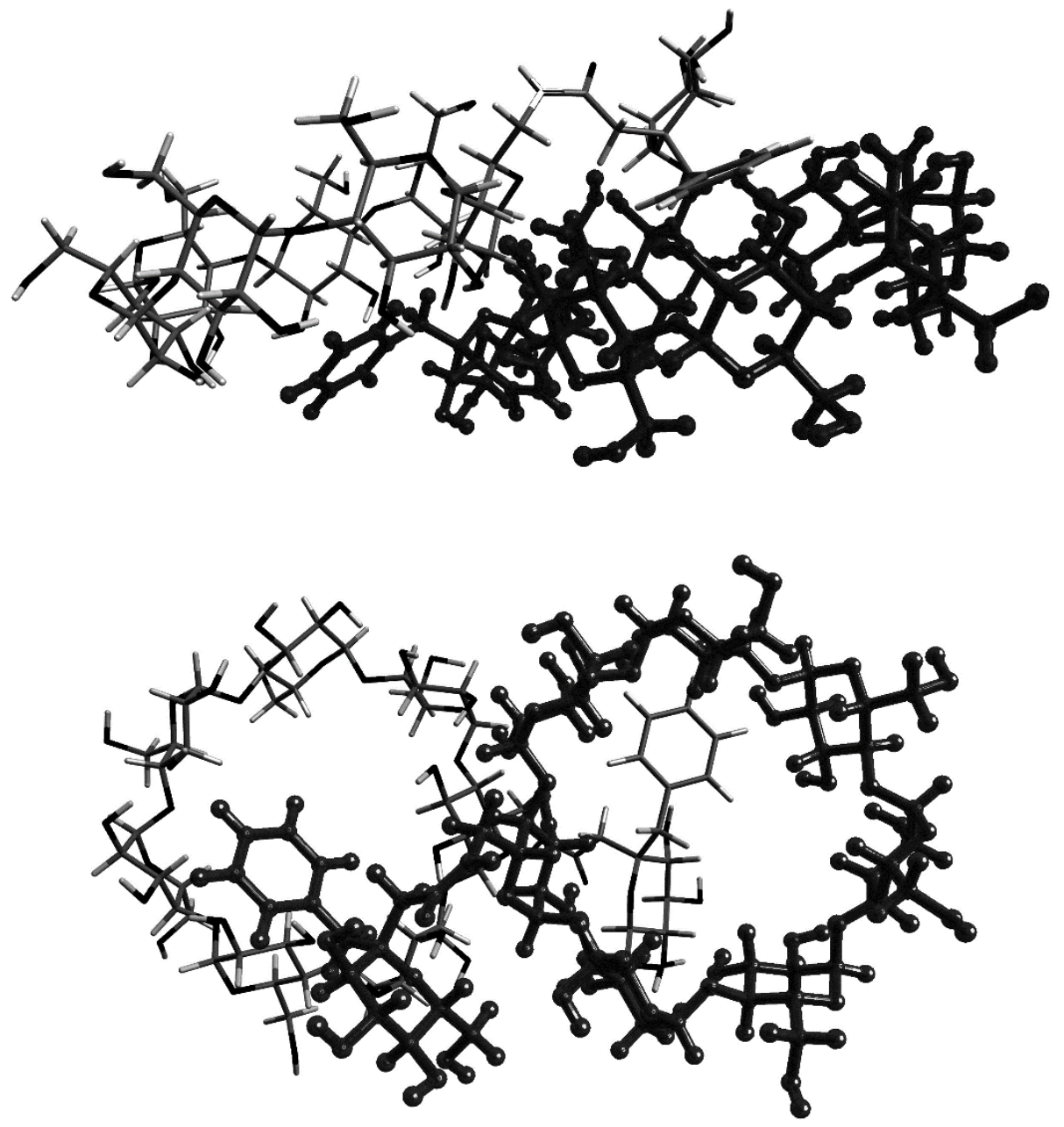

Fig 6. Molecular modeling of the pseudo-dimeric structure of $\mathbf{1}$ 